\title{
Synthesis, Characterization, and Tribological Behavior of Oleic Acid Capped Graphene Oxide
}

\author{
Tiedan Chen, ${ }^{1,2,3}$ Yanqiu Xia, ${ }^{1}$ Zhengfeng Jia, ${ }^{1,4,5}$ Zhilu Liu, ${ }^{1}$ and Haobo Zhang ${ }^{6}$ \\ ${ }^{1}$ State Key Laboratory of Solid Lubrication, Lanzhou Institute of Chemical Physics, Chinese Academy of Sciences, \\ Lanzhou 730000, China \\ ${ }^{2}$ Huaibei Normal University, School of Chemistry and Materials Science, Huaibei 235000, China \\ ${ }^{3}$ Graduate School of Chinese Academy of Sciences, Beijing 100039, China \\ ${ }^{4}$ College of Materials Science and Engineering, Liaocheng University, Liaocheng 252059, China \\ ${ }^{5}$ School of Materials Science and Engineering, Central South University, Changsha 410083, China \\ ${ }^{6}$ Gansu University of Traditional Chinese Medicine, Lanzhou 730000, China \\ Correspondence should be addressed to Yanqiu Xia; xiayq@licp.cas.cn
}

Received 4 November 2013; Revised 17 December 2013; Accepted 24 December 2013; Published 3 February 2014

Academic Editor: Jinlong Jiang

Copyright (C) 2014 Tiedan Chen et al. This is an open access article distributed under the Creative Commons Attribution License, which permits unrestricted use, distribution, and reproduction in any medium, provided the original work is properly cited.

\begin{abstract}
Graphene oxide (GO) nanosheets were prepared by modified Hummers and Offeman methods. Furthermore, oleic acid (OA) capped graphene oxide (OACGO) nanosheets were prepared and characterized by means of Fourier transform-infrared spectroscopy (FT-IR), transmission electron microscopy (TEM), and X-ray diffraction (XRD). At the same time, the friction and wear properties of OA capped graphite powder (OACG), OACGO, and oleic acid capped precipitate of graphite (OACPG) as additives in poly-alpha-olefin (PAO) were compared using four-ball tester and SRV-1 reciprocating ball-on-disc friction and wear tester. By the addition of OACGO to PAO, the antiwear ability was improved and the friction coefficient was decreased. Also, the tribological mechanism of the GO was investigated.
\end{abstract}

\section{Introduction}

Graphene has recently attracted extensive attention because of its excellent properties, such as high thermal conductivity, high young's modulus, large specific surface area, and outstanding tribological properties [1-4]. These excellent properties have opened new pathways for developing a wide range of novel functional materials, for example, solar cells, field-effect device, nanocomposites, antiwear materials, and so forth [5-8]. It is well known that graphene is oneatom layer thick carbon sheet. Graphene possesses excellent tribological properties because of its small size and extremely thin laminated structure. The graphene platelets easily enter the contact area during sliding, preventing the rough surfaces from coming into direct contact. Lin et al. [9] synthesized stearic acid and oil acid modified graphene using chemical methods. The modified graphene was dispersed into 350SN base oil as additives. The four-ball test exhibited that the wear resistance and load-carrying capacity of the lubricating oil were greatly improved with the addition of the modified graphene. Huang et al. [10] synthesized graphite nanosheets with average diameter of $500 \mathrm{~nm}$ and thickness of about $15 \mathrm{~nm}$ by stirring ball milling. The tribological behavior of the graphite nanosheets as additive in paraffin oil was also investigated using a four-ball and a pin-on-disk friction and wear tester. The results showed that load-carrying capacity and antiwear ability of the lubricating oil were improved and the friction coefficient of the base oil was decreased by the addition of the graphite nanosheets. However, in the paper, the XRD analysis revealed that the graphite nanosheets were not graphene nanosheets. In general, chemical oxidation method (Hummers and Offeman) produces graphene by first inserting functional groups such as carbonyl, hydroxyl, and peroxyl in carbon layers of graphite. The functional groups weakened the force between the carbon layers, which causes the graphene layers to peel off layer by layer from graphite. The resulting graphene oxide can be reduced to graphene by adding hydrazine into the graphene oxide solution [11]. 
However, the realization of the potential of the graphene is difficult because of the lack of the functional group in graphene. The abundant oxygenous groups in graphene oxide molecules make it feasible to interact with other functional groups [12]. So many works try to study the properties of the GO. Song et al. [13] investigated the tribological behaviors of the poly(ether ketone) (PEEK) composites filled with GO nanosheets. The result showed that the GO-Si-filled PEEK possessed an excellent friction reducing and antiwear properties when the applied load and the sliding speed are $2.94 \mathrm{~N}$ and $0.0628 \mathrm{~m} / \mathrm{s}$, respectively. The outstanding properties of the composites are possibly attributed to the self-lubricity of the GO-Si nanosheets. Tai et al. [14] fabricated a series of GO/ultrahigh molecular weight polyethylene (UHMWPE) through an optimized toluene-assisted mixing followed by hot-pressing. The tribological behavior of the GO/UHMWPE was investigated using high speed reciprocating friction testing machine. When the content of the added GO nanosheets was up to $1.0 \mathrm{wt} \%$, the wear resistance of the composites increased lightly due to the formation of the transfer film of the UHMWPE. Li et al. [15] synthesized GO/nitrile rubber (NBR) nanocomposites using a solution-mixing method. Under dry sliding condition, the friction coefficient and wear rate of the GO/NBR composites were decreased dramatically with a lower concentration of GO. Possibly, the GO easily transferred from matrix to form a continuous transfer film during sliding, decreasing the friction coefficient and wear rate. Liu et al. [16] synthesized full exfoliation GO with an improved Hummers' method. The polyimide (PI) and PI/GO nanocomposites were also prepared via a polymerization of monomer reactants process. The friction and wear testing results showed that the addition of GO evidently improved the tribological properties of the PI. Song and Li [17] also synthesized GO nanosheets with modified Hummers and Offeman methods. The tribological behavior of the oxide graphene nanosheets as water-based lubricant additive was investigated using a UMT-2 ball-plate tribotester. With the addition of GO nanosheets in pure water, the antiwear ability was improved and the friction coefficient was decreased. They believed that the formation of a thin physical tribofilm on the substrate can explain the good friction and wear properties of GO nanosheets.

Based on the above discussion, the GO possesses an excellent tribological property, mixed into polymer or waterbased lubricant. In this paper, the GO nanosheets were synthesized by modified Hummers and Offeman methods and were capped with OA using chemical method. The tribological properties of the PAO containing OACGO were investigated using quenched AISI 1045 steel/AISI 52100 steel couples. Furthermore, the mechanism of the antiwear was also discussed.

\section{Experimental}

GO, a two dimensional solid in bulk form, was prepared from natural graphite powder by oxidizing natural graphite powder in the presence of $\mathrm{KMnO}_{4}$ in concentrated $\mathrm{H}_{2} \mathrm{SO}_{4}$ according to modified Hummer's method [18]. Simply, $4 \mathrm{~g}$ of

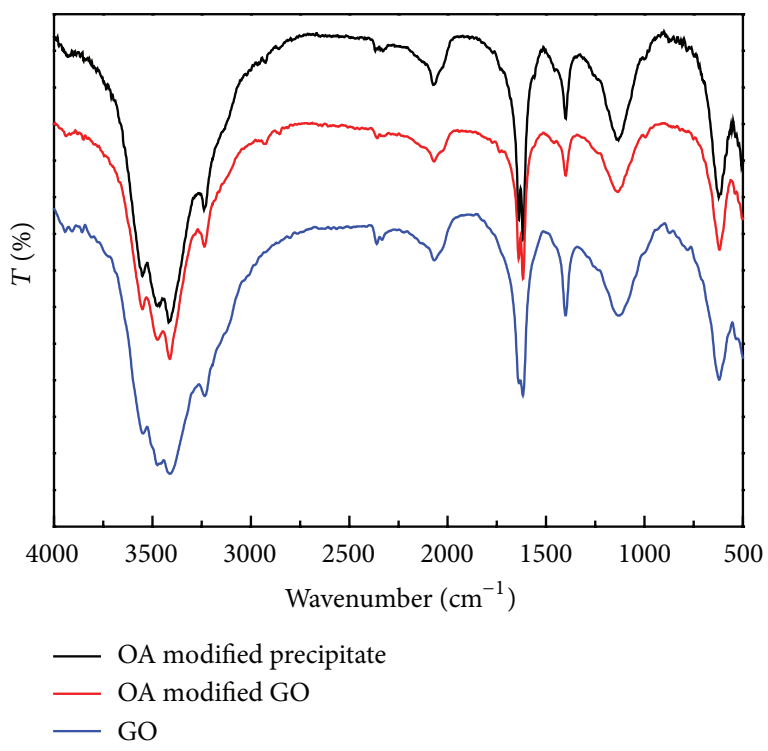

Figure 1: FT-IR spectra of the GO, OA modified GO, and OA modified precipitate.

graphite powder and $4 \mathrm{~g}$ of $\mathrm{NaNO}_{3}$ were added to $200 \mathrm{~mL}$ of cooled $\left(0^{\circ} \mathrm{C}\right)$ concentrated $\mathrm{H}_{2} \mathrm{SO}_{4}$ slowly with stirring, in a $1000 \mathrm{~mL}$ breaker. $30 \mathrm{~g}$ of $\mathrm{KMnO}_{4}$ was added gradually with stirring and cooling $\left(0^{\circ} \mathrm{C}\right)$; then, the reaction was carried out for $90 \mathrm{~min}$. For work up, the mixture was cooled to room temperature and poured into cold $\left(0^{\circ} \mathrm{C}\right)$ deionized water. Successively, $30 \% \mathrm{H}_{2} \mathrm{O}_{2}$ was slowly added into the mixture until the solution turned bright yellow. The solid product was separated by centrifugation and washed repeatedly with $5 \%$ $\mathrm{HCl}$ solution and deionized water, until the $\mathrm{PH}$ of the mixture was neutral. The GO was obtained by centrifugation with the speed of 4000 round per minute, and the precipitate of the centrifugation was also retained for comparison.

$3.0 \mathrm{~g} \mathrm{GO}$ and its precipitate were put into $60 \mathrm{~mL}$ ethanol with ultrasonic cleaner to form homogeneous slurry, respectively. With $2 \mathrm{~g} \mathrm{OA}$, the homogeneous slurry was transferred into a round-bottom flask and stirred under reflux conditions for $0.5 \mathrm{~h}$. Finally, the ethanol was distilled away under reduced pressure and washed with ultrasound several times to obtain the oleic acid capped GO and oleic acid capped precipitate (OACPG), respectively $[19,20]$.

The commercial PAO, kinetic viscosity of $68 \mathrm{~mm}^{2} / \mathrm{s}$ at $40^{\circ} \mathrm{C}$, was used as the base oil and the added content (mass fraction) of the individual OACGO, OACG, and OACPG were all selected with concentrations of $0.5 \%, 1.0 \%, 1.5 \%$, and $2.0 \%$. Every mixture forms a stable dispersion in PAO, and no sedimentation was observed after 7 days at room temperature. The friction and wear behavior of the quenched AISI 1045 steel lubricated with pure PAO and PAO containing additives (1.0 wt\%) were investigated by SRV reciprocating ball-on-disc friction and wear tester. The upper balls of $10 \mathrm{~mm}$ in diameter were made of AISI 52100 steel. The lower stationary discs were made of quenched AISI 1045 steel (Ø $24 \mathrm{~mm} \times 7.8 \mathrm{~mm}$ ) with a surface roughness of $0.03 \mu \mathrm{m}$ and hardness of $640 \mathrm{HV}$. The sliding tests were executed at 


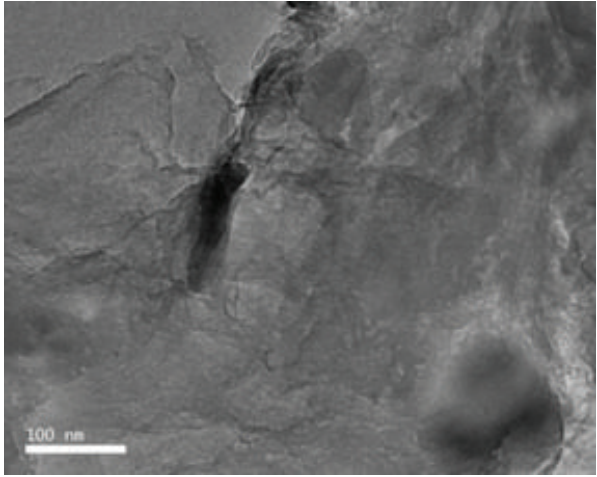

(a)

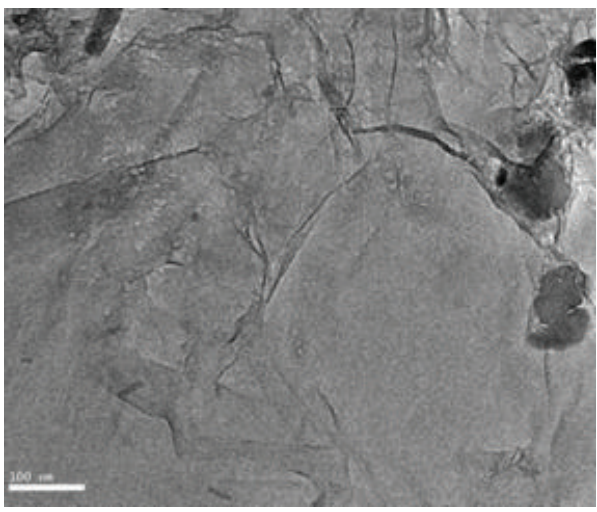

(c)

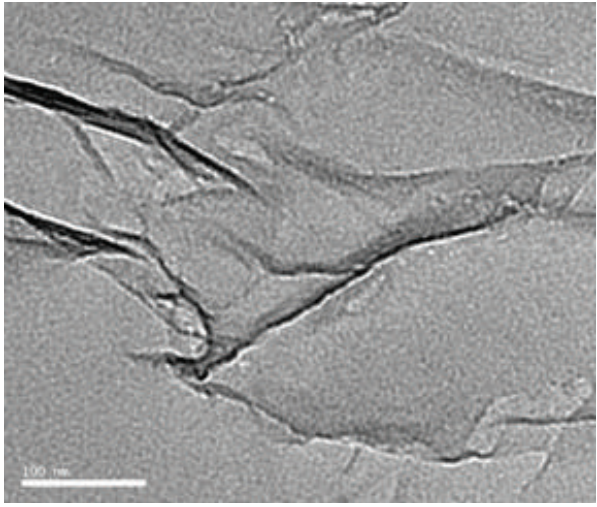

(e)

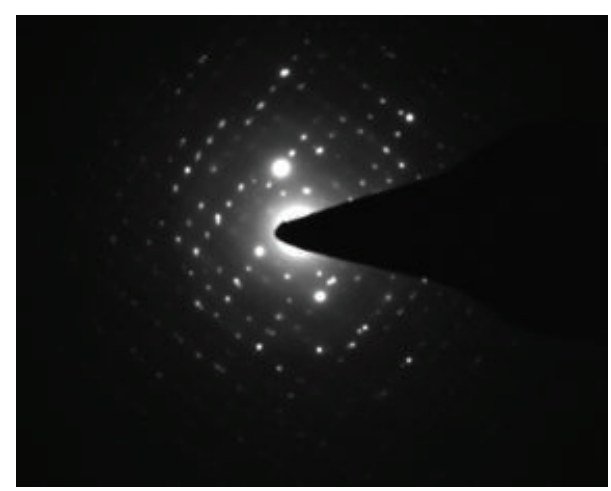

(b)

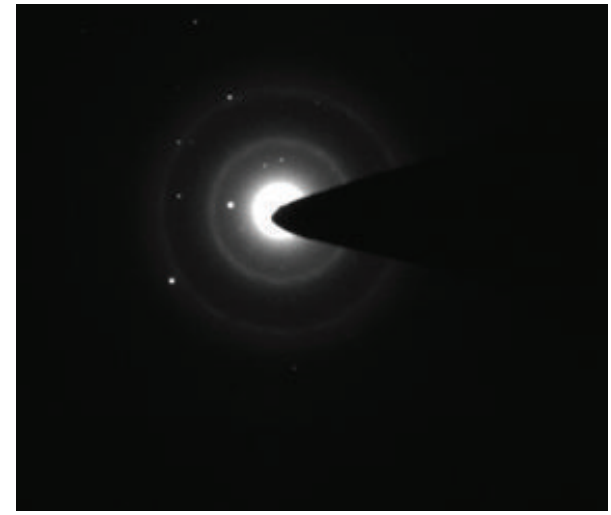

(d)

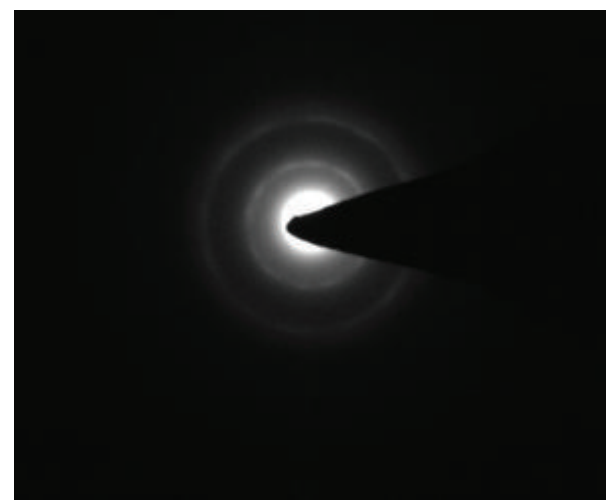

(f)

FIGURE 2: The TEM and SAED analysis of the graphite ((a), (b)), precipitate ((c), (d)), and GO ((e), (f)).

amplitude of $1 \mathrm{~mm}$, test duration of $30 \mathrm{~min}$, normal load of $40 \mathrm{~N}$, and reciprocating frequencies of $10,20,30,40$, and $50 \mathrm{~Hz}$ at room temperature. Separate tests were performed for each frequency and three repeat measurements were performed, and the averaged coefficients of friction and wear rates are given herein. The antiwear properties of three lubricants were evaluated by MRS-10A four-ball machine (the ball, with a diameter of $12.7 \mathrm{~mm}$, was made of AISI 52100 steel), and the testing conditions were selected as rotating rate of $1450 \mathrm{rpm}$, running duration of 30 minutes, load of $392 \mathrm{~N}$, and room temperature. The FT-IR spectrum was analyzed in the range of $500-4000 \mathrm{~cm}^{-1}$ by a Bruck IFs66v spectrometer. Transmission electron microscopy (TEM) images of the samples were obtained by a JEM-1200 EX TEM. X-ray diffraction (XRD) was done on X'Pert-MRD $\mathrm{X}$-ray diffractometer $(40 \mathrm{kV}, 30 \mathrm{~mA}, \mathrm{Cu} \mathrm{K} \alpha$ radiation). $\mathrm{X}$ ray photoelectron spectroscopy (XPS) was executed on a PHI-5702 multifunctional X-ray photoelectron spectroscope to evaluate the chemical states of the worn surface. Al-K $\alpha$ radiation was used as the excitation source to determine the binding energies of the target elements at pass energy of $29.4 \mathrm{eV}$ and a resolution of $\pm 0.2 \mathrm{eV}$. The binding energy of C1s $(284.6 \mathrm{eV})$ was used as the internal reference [21]. The morphologies and elemental composition of the worn 


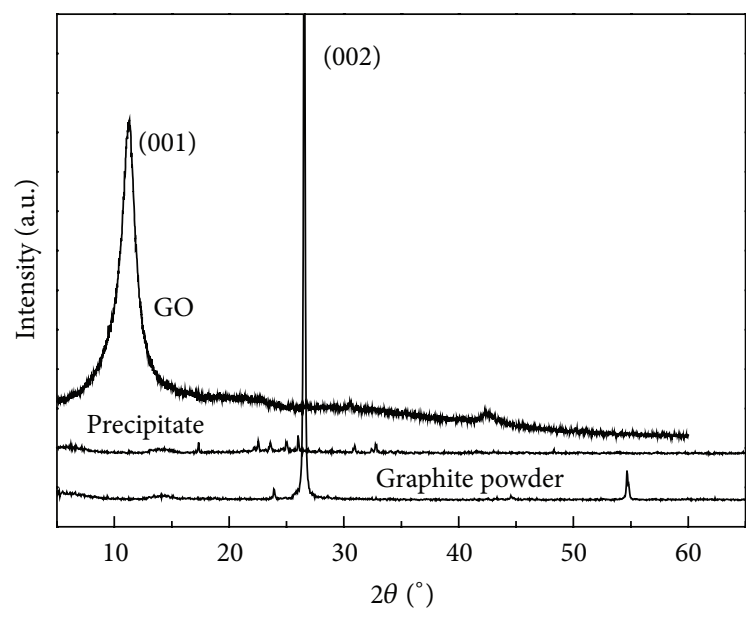

FIgURE 3: The XRD curves of the graphite, precipitate, and GO.

surfaces were analyzed by a JSM-6500LV scanning electron microscope equipped with an attachment for energy dispersive X-ray analysis (SEM-EDXA, Kevex Sigma, USA); the worn surfaces of AISI 1045 steels were ultrasonically washed with acetone and analyzed using SEM. The thermogravimetry (TG) test was carried out on Netzsch STA499 simultaneous thermal analyzer at a heating rate of $10^{\circ} \mathrm{C} \mathrm{min}{ }^{-1}$ under $\mathrm{N}_{2}$. The wear volume loss of the lower discs was determined using a Microxam three dimensional surface profiler (3D) (ADE Corporation of America).

\section{Results and Discussion}

3.1. Characterization of GO. Figure 1 shows the FT-IR curves of the GO, OA modified GO, and OA modified precipitate. The absorbance band at about $3425 \mathrm{~cm}^{-1}$ could be assigned to the $\mathrm{O}-\mathrm{H}$ stretching vibration and the $\mathrm{O}-\mathrm{H}$ stretching modes of intercalated water. The spectrum of $1620 \mathrm{~cm}^{-1}$ indicates that $\mathrm{sp}^{2}$ of $\mathrm{C}=\mathrm{C}$ was unoxidized $[15,16]$. The bands at about $1400 \mathrm{~cm}^{-1}$ and $1140 \mathrm{~cm}^{-1}$ could be attributed to the $\mathrm{C}-\mathrm{OH}$ stretching vibration and $\mathrm{C}-\mathrm{O}$ stretching vibration [17]. As for the OA modified GO and precipitate, the bands at $2925 \mathrm{~cm}^{-1}$ and $2858 \mathrm{~cm}^{-1}$ indicate the band of $\mathrm{C}-\mathrm{H}$ stretching of the alkyl chain [22].

Figure 2 shows the TEM images and corresponding ED (electric diffraction) patterns of the GO, precipitate, and graphite. Obviously, the GO was the result of the full oxidation of the graphite, so the crystal structure of the graphite was destroyed during the oxidation process. It can also be seen that the crystal structure of the precipitate was also destroyed seriously. The low contrast feature indicates the small thickness of the GO [23].

$\mathrm{XRD}$ is a valuable method to investigate the interlayer changes and the crystalline properties of the materials. Figure 3 shows the XRD profiles of the graphite, precipitate, and GO. The graphite revealed a sharp and intensive peak at $2 \theta=$ $26.6^{\circ}$, exhibiting a highly ordered crystal structure with an interlayer spacing of $0.33 \mathrm{~nm}$ [23]. After oxidation, the 002 diffraction peak of graphite powder disappeared, revealing

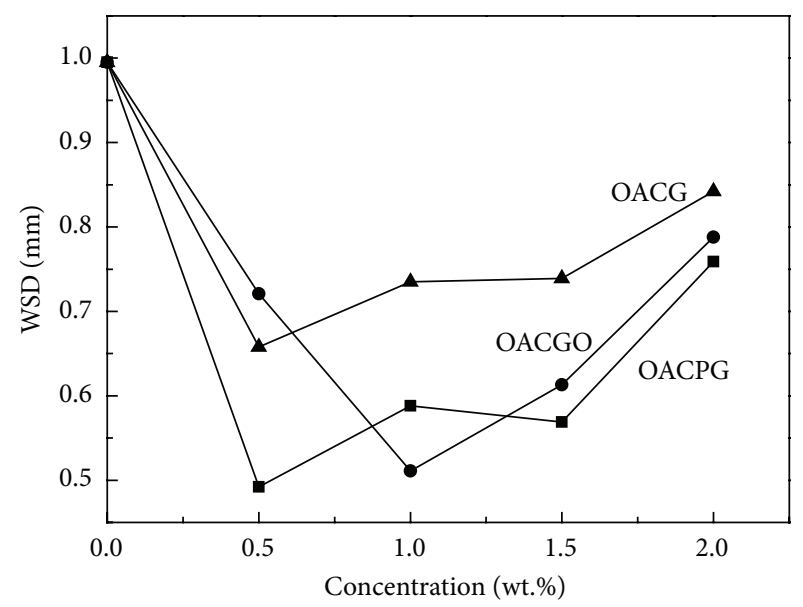

Figure 4: The WSD of the OACG, OACGO, and OACPG as additives.

the full oxidation of the graphite. GO pattern shows a weak characteristic peak at $2 \theta=10.8^{\circ}$, corresponding to interlayer spacing of $0.7 \mathrm{~nm}$. As for the precipitate, the 002 diffraction peak of graphite powder weakened very much, showing much oxidation of graphite.

3.2. Friction and Wear Properties of OACGO. Figure 4 shows the wear scare diameter (WSD) under the three additives at different contents with four-ball testing. It can be seen that the WSD decreased rapidly as the three compounds were added into base oil. Namely, the WSD of the lubricants containing OACPG decreased from $1.0 \mathrm{~mm}$ to $0.48 \mathrm{~mm}$ at the concentration of $0.5 \%$. Moreover, the WSD of the PAO + OACGO was about $0.5 \mathrm{~mm}$, much lower than pure base oil. Comparing the three additives, we found that the WSD of the OACGO and OACPG were lower than that of OACG under the concentration higher than $1.0 \%$.

Figure 5(a) shows the friction coefficient frequency curves of quenched AISI 1045 steel sliding against AISI 52100 steel balls under the lubrication of PAO, PAO + OACGO, and PAO + OACPG (1.0\% content) by SRV test. Under the lubrication of the PAO + OACGO and PAO + OACPG, lower friction coefficients were recorded than those under the lubrication of the pure PAO. For example, at a frequency of $30 \mathrm{~Hz}$, an average coefficient of friction for PAO + OACGO was about 0.09 , and it rose to 0.36 for pure PAO. Comparing the friction coefficient of PAO + OACGO and PAO + OACPG, we found that the friction coefficient of the PAO + OACGO was lower than that of the PAO + OACPG. In detail, the friction coefficient of PAO + OACPG was 0.15, higher than that of PAO + OACGO. Figure 5(b) plots the wear rate of the AISI 1045 steel lubricated with the three lubricants. Obviously, the wear rate of the pure PAO was higher than the other two lubricants. At a frequency of $20 \mathrm{~Hz}$, the wear rate of the pure PAO was $1.4 \times 10^{-2} \mu \mathrm{m}^{3} / \mathrm{Nm}$, but those of $\mathrm{PAO}+\mathrm{OACGO}$ and PAO $+\mathrm{OACPG}$ were $0.8 \times 10^{-2} \mu \mathrm{m}^{3} / \mathrm{Nm}$ and $0.2 \times 10^{-2} \mu \mathrm{m}^{3} / \mathrm{Nm}$, respectively. The wear rate of PAO + OACGO was lower than that of PAO + OACPG under all the frequencies. 


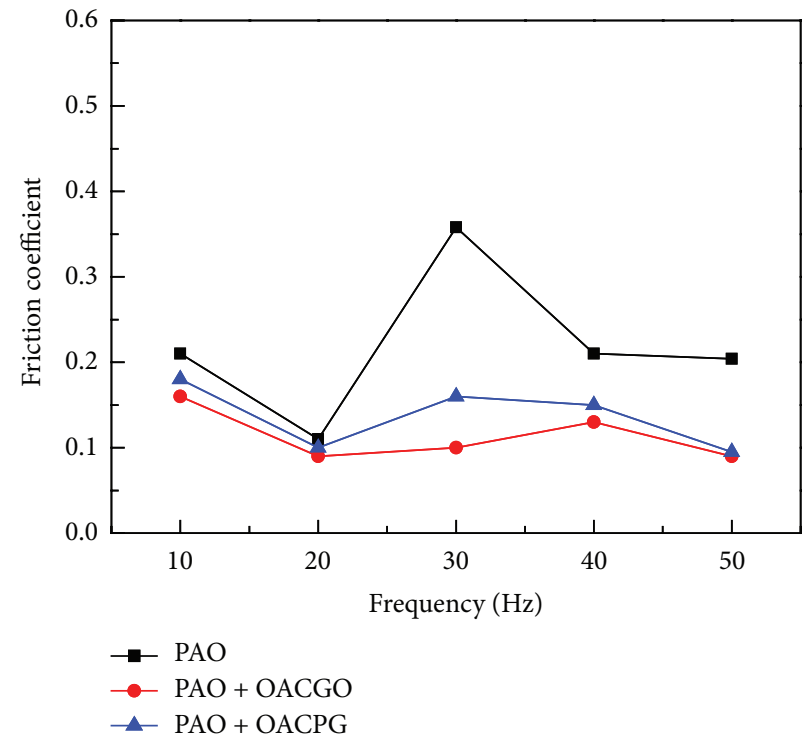

(a)

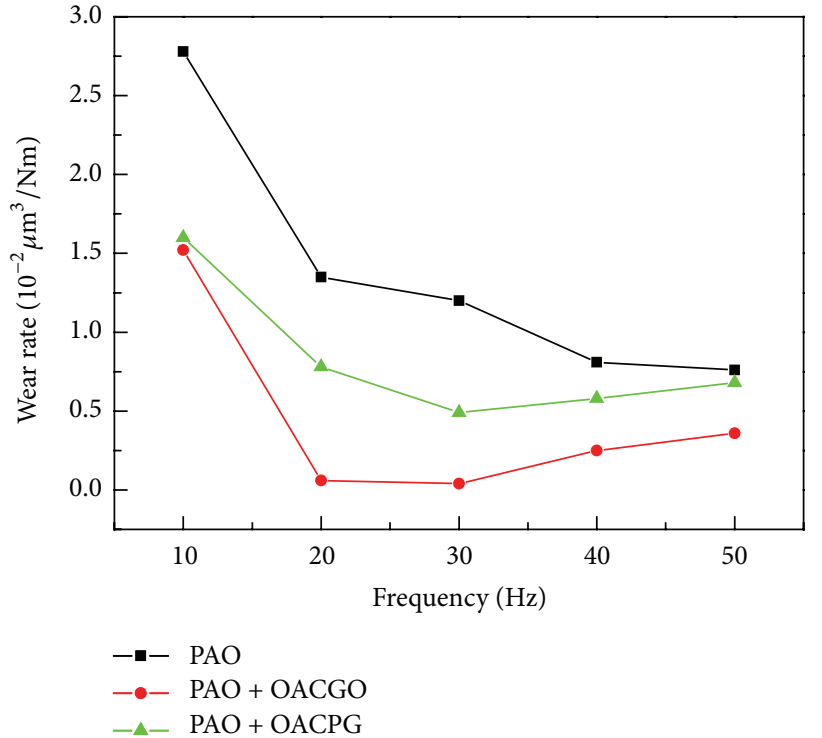

(b)

FIGURE 5: The friction coefficient and wear rate of the PAO, PAO + OACGO, and PAO + OACPG.

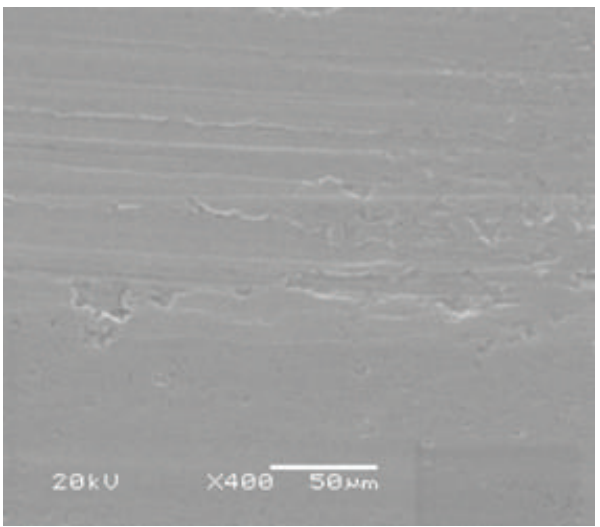

(a)

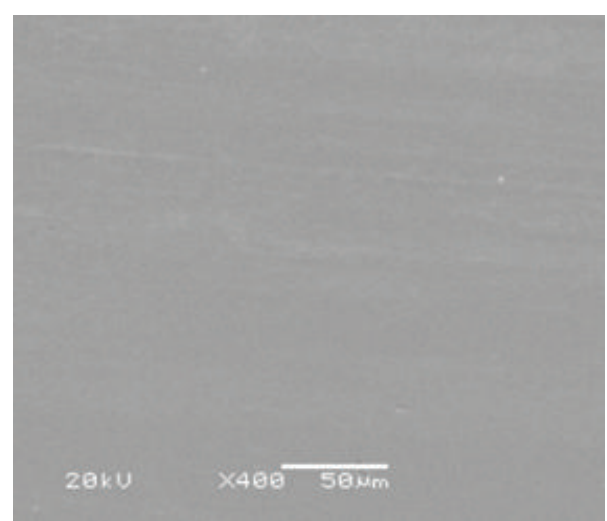

(b)

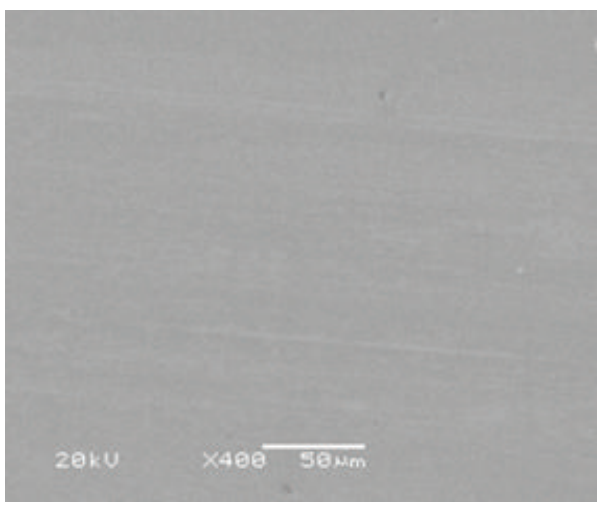

(c)

FIGURE 6: The SEM images of the worn surface of the low disc lubricated with PAO (a), PAO + OACGO (b), and PAO + OACPG (c). 


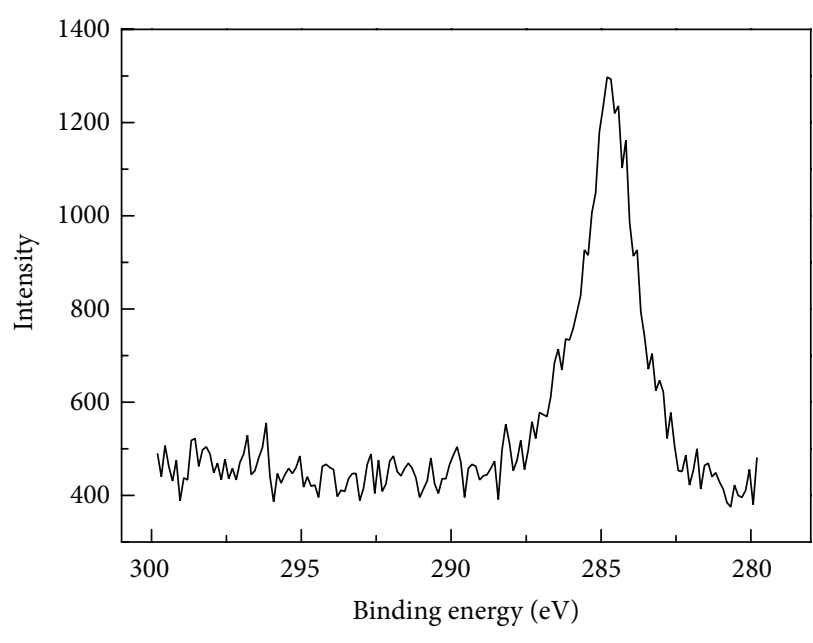

$-\mathrm{C} 1 \mathrm{~s}$

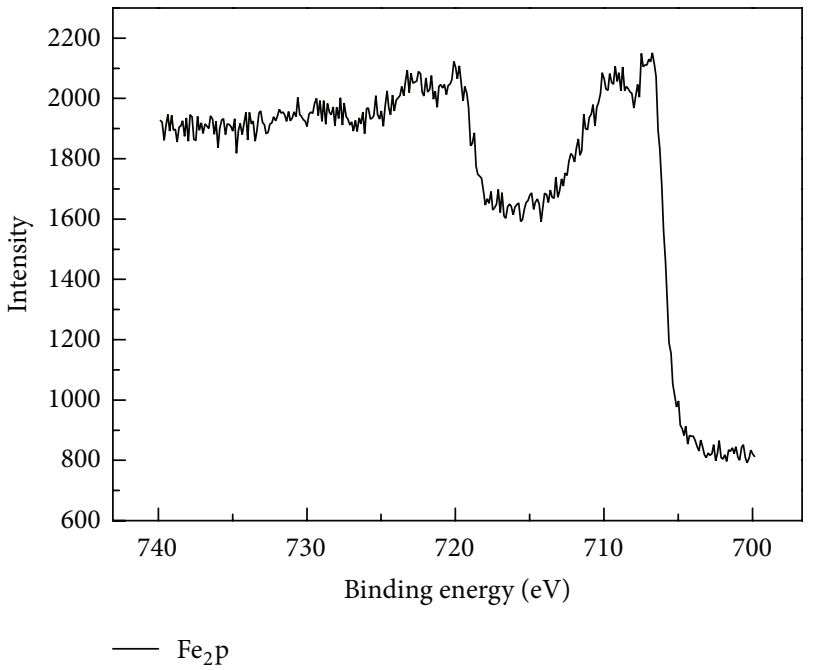

(b)

(a)

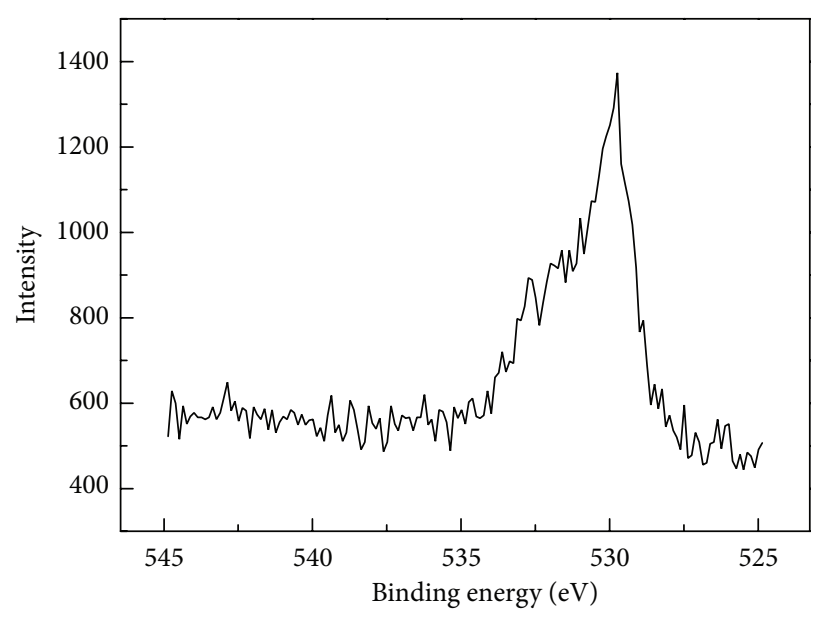

O1s

(c)

FIGURE 7: The XPS analysis of the PAO + OACGO lubricated AISI 1045 steel.

3.3. SEM and XPS Analysis of the Worn Surface. Figure 6 reveals the SEM images of the worn surfaces of the low disc of AISI 1045 steels lubricated with PAO, PAO + OACGO, and PAO + OACPG. As for the steel/steel pair, the worn surfaces of the lower disc under the lubrication of the PAO + OACGO and PAO + OACPG appear smoother and with slighter adhesion in comparison with that of the pure PAO at a frequency of $30 \mathrm{~Hz}$ for 30 minutes, corresponding well to the wear rate of the AISI 1045 steel and four-ball test (see Figures 4 and 5). Moreover, the wear scare of the PAO + OACGO was slighter than that of the PAO + OACPG.

The worn surfaces of the lower disc lubricated with $\mathrm{PAO}+$ OACGO were analyzed by XPS for acquiring more information about the tribochemical reactions during sliding. Figure 7 depicts the XPS spectra of C1s, O1s, and $\mathrm{Fe}_{2}$ p on the worn surface of AISI 1045 steel lubricated with PAO + OACGO. O1s peak at $529.7 \mathrm{eV}$ was assigned to metal oxides and $\mathrm{Fe}_{2} \mathrm{O}_{3}$. $\mathrm{Fe}_{2}$ p peak from $706.5 \mathrm{eV}$ to $710.2 \mathrm{eV}$ was attributed to $\mathrm{Fe}$
TABLE 1: The atomic concentration of elements on the worn surface of PAO and PAO + OACGO lubricated AISI 1045 steel.

\begin{tabular}{lccc}
\hline Lubricants & \multicolumn{3}{c}{ Atomic concentration } \\
& $\mathrm{C}(\%)$ & $\mathrm{O}(\%)$ & $\mathrm{Fe}(\%)$ \\
\hline PAO + OACGO & 57.46 & 16.40 & 26.14 \\
PAO & 40.55 & 19.57 & 39.88 \\
\hline
\end{tabular}

and $\mathrm{Fe}_{2} \mathrm{O}_{3}$. The peak of $\mathrm{Cls}$ at $284.7 \mathrm{eV}$ might be assigned to carbon [21]. So it is reasonable to induct that the tribofilm containing $\mathrm{C}, \mathrm{O}$, and Fe formed on the worn surface. To collect more information of the tribochemical reactions, the atomic concentrations of elements on the worn surface of $\mathrm{PAO}$ and PAO + OACGO lubricated AISI 1045 steel were shown in Table 1. Obviously, the atomic concentration of $\mathrm{C}$ on the worn surface of AISI 1045 steel lubricated with PAO + OACGO was $57.46 \%$, higher than that with pure PAO. On 
the other hand, the atomic concentration of the $\mathrm{Fe}$ on the worn surface lubricated with PAO + OACGO was $26.14 \%$, lower than that of pure PAO of $39.88 \%$. We can draw a conclusion that the tribofilm of the PAO + OACGO was thicker than that of pure PAO and the GO nanosheets exist on the worn surface. Similarly, Lin and Song $[9,13]$ suggested that the nanosheets entered the contact during sliding and a thin physical tribofilm was formed on the metal substrate. So the tribofilm could not only bear the load of the steel ball, but also prevent from directing contact with the metal surface. The antiwear ability was improved and the friction coefficient was reduced significantly. So it is reasonable to presume that the GO nanosheets entered the contact during sliding and formed a thick tribofilm on the worn surface of the AISI 1045 steel. The thick tribofilm possessed antiwear and friction reducing properties.

\section{Conclusions}

The Following conclusions can be drawn from above results.

(1) The XRD analysis showed that the 002 diffraction peak of graphite powder disappeared after oxidation. GO pattern showed a weak characteristic peak at $2 \theta=10.8^{\circ}$, corresponding to interlayer spacing of $0.7 \mathrm{~nm}$.

(2) With the addition of $1.0 \%$ OACGO in PAO, the WSD decreased from $1.0 \mathrm{~mm}$ to $0.52 \mathrm{~mm}$. Moreover, the wear rate of the PAO + OACGO was also much lower than that of pure PAO.

(3) XPS analysis showed that a thicker tribofilm formed during sliding with PAO + OACGO than that with pure PAO. It is presumed that the GO nanosheets entered the contact during sliding and formed a thick carbon film. The carbon film possesses the friction reducing and antiwear properties.

\section{Conflict of Interests}

The authors declare that there is no conflict of interests regarding the publication of this paper.

\section{Acknowledgments}

Thanks are due the financial support of this work by Natural Science Foundation of China (Grant No. 51172102) and Open Project of State Key Laboratory of Solid Lubrication, Lanzhou Institute of Chemical Physics, Chinese Academy of Sciences.

\section{References}

[1] H. Y. Mao, Y. H. Lu, J. D. Lin et al., "Manipulating the electronic and chemical properties of graphene via molecular functionalization," Progress in Surface Science, vol. 88, no. 2, pp. 132159, 2013.

[2] Y. Q. Li, D. Y. Pan, S. B. Chen et al., "In situ polymerization and mechanical, thermal properties of polyurethane/graphene oxide/epoxy nanocomposites," Materials and Design, vol. 47, pp. 850-856, 2013.
[3] S. Park and S. Kim, "Effect of carbon blacks filler addition on electrochemical behaviors of $\mathrm{Co}_{3} \mathrm{O}_{4}$ /graphene nanosheets as a supercapacitor electrode," Electrochimica Acta, vol. 89, pp. 516522, 2013.

[4] Y. L. Zhang, Y. P. Liu, J. M. He et al., "Electrochemical behavior of graphene/Nafion/Azure I/Au nanoparticles composites modified glass carbon electrode and its application as nonenzymatic hydrogen peroxide sensor," Electrochimica Acta, vol. 90, pp. 550-555, 2013.

[5] D. Berman, A. Erdemir, and A. V. Sumant, "Few layer graphene to reduce wear and friction on sliding steel surfaces," Carbon, vol. 54, pp. 454-459, 2013.

[6] G. N. Ren, Z. Z. Zhang et al., "Influence of functional graphene as filler on the tribological behaviors of Nomex fabric/phenolic composite," Composites A, vol. 49, pp. 157-164, 2013.

[7] K. J. Huang, L. Wang, J. Li, and Y. M. Liu, "Electrochemical sensing based on layered $\mathrm{MoS}_{2}$-graphene composites," Sensors and Actuators B, vol. 178, pp. 671-677, 2013.

[8] C. M. Praveen Kumar, T. V. Venkatesha, and R. Shabadi, "Preparation and corrosion behavior of $\mathrm{Ni}$ and $\mathrm{Ni}$-graphene composite coatings," Materials Research Bulletin, vol. 48, pp. 1477-1483, 2013.

[9] J. Lin, L. Wang, and G. Chen, "Modification of graphene platelets and their tribological properties as a lubricant additive," Tribology Letters, vol. 41, no. 1, pp. 209-215, 2011.

[10] H. D. Huang, J. P. Tu, L. P. Gan, and C. Z. Li, "An investigation on tribological properties of graphite nanosheets as oil additive," Wear, vol. 261, no. 2, pp. 140-144, 2006.

[11] F. Y. Ban, S. R. Majid, N. M. Huang, and H. N. Lim, "Graphene oxide and its electrochemical performance," International Journal of Electrochemical Science, vol. 7, pp. 4345-4351, 2012.

[12] J. Ou, J. Wang, S. Liu et al., "Tribology study of reduced graphene oxide sheets on silicon substrate synthesized via covalent assembly," Langmuir, vol. 26, no. 20, pp. 15830-15836, 2010.

[13] H. J. Song, N. Li et al., "Preparation and tribological properties of graphene/poly(ether ether ketone) nanocomposites," Journal of Materials Science, vol. 47, no. 17, pp. 6436-6443, 2012.

[14] Z. Tai, Y. Chen, Y. An, X. Yan, and Q. Xue, "Tribological behavior of UHMWPE reinforced with graphene oxide nanosheets," Tribology Letters, vol. 46, no. 1, pp. 55-63, 2012.

[15] Y. Li, Q. Wang, T. Wang, and G. Pan, "Preparation and tribological properties of graphene oxide/nitrile rubber nanocomposites," Journal of Materials Science, vol. 47, no. 2, pp. 730-738, 2012.

[16] H. Liu, Y. Li, T. Wang, and Q. Wang, "In situ synthesis and thermal, tribological properties of thermosetting polyimide/ graphene oxide nanocomposites," Journal of Materials Science, vol. 47, no. 4, pp. 1867-1874, 2012.

[17] H.-J. Song and N. Li, "Frictional behavior of oxide graphene nanosheets as water-base lubricant additive," Applied Physics A, vol. 105, no. 4, pp. 827-832, 2011.

[18] W. S. Hummers Jr. and R. E. Offeman, "Preparation of graphitic oxide," Journal of the American Chemical Society, vol. 80, no. 6 , p. 1339, 1958.

[19] Z. Jia and Y. Xia, "Hydrothermal synthesis, characterization, and tribological behavior of oleic acid-capped lanthanum borate with different morphologies," Tribology Letters, vol. 41, no. 2, pp. 425-434, 2011.

[20] Z. F. Jia, Y. C. Su, Y. Q. Xia et al., "Synthesis, characterization, and tribological behavior of oleic acid capped calcium borate hydrate," Tribology Transactions, vol. 56, no. 3, pp. 521-529, 2013. 
[21] J. F. Moulder, W. F. Stickle, P. E. Sobol, and K. D. Bomben, Handbook of X-Ray Photoelectron Spectroscopy, Physical Electronics, 1995.

[22] Y. Gao, X. Chen, H. Xu et al., "Highly-efficient fabrication of nanoscrolls from functionalized graphene oxide by LangmuirBlodgett method," Carbon, vol. 48, no. 15, pp. 4475-4482, 2010.

[23] C. Wang, L. Zhan, W.-M. Qiao, and L.-C. Ling, "Preparation of graphene nanosheets through detonation," New Carbon Materials, vol. 26, no. 1, pp. 21-25, 2011. 

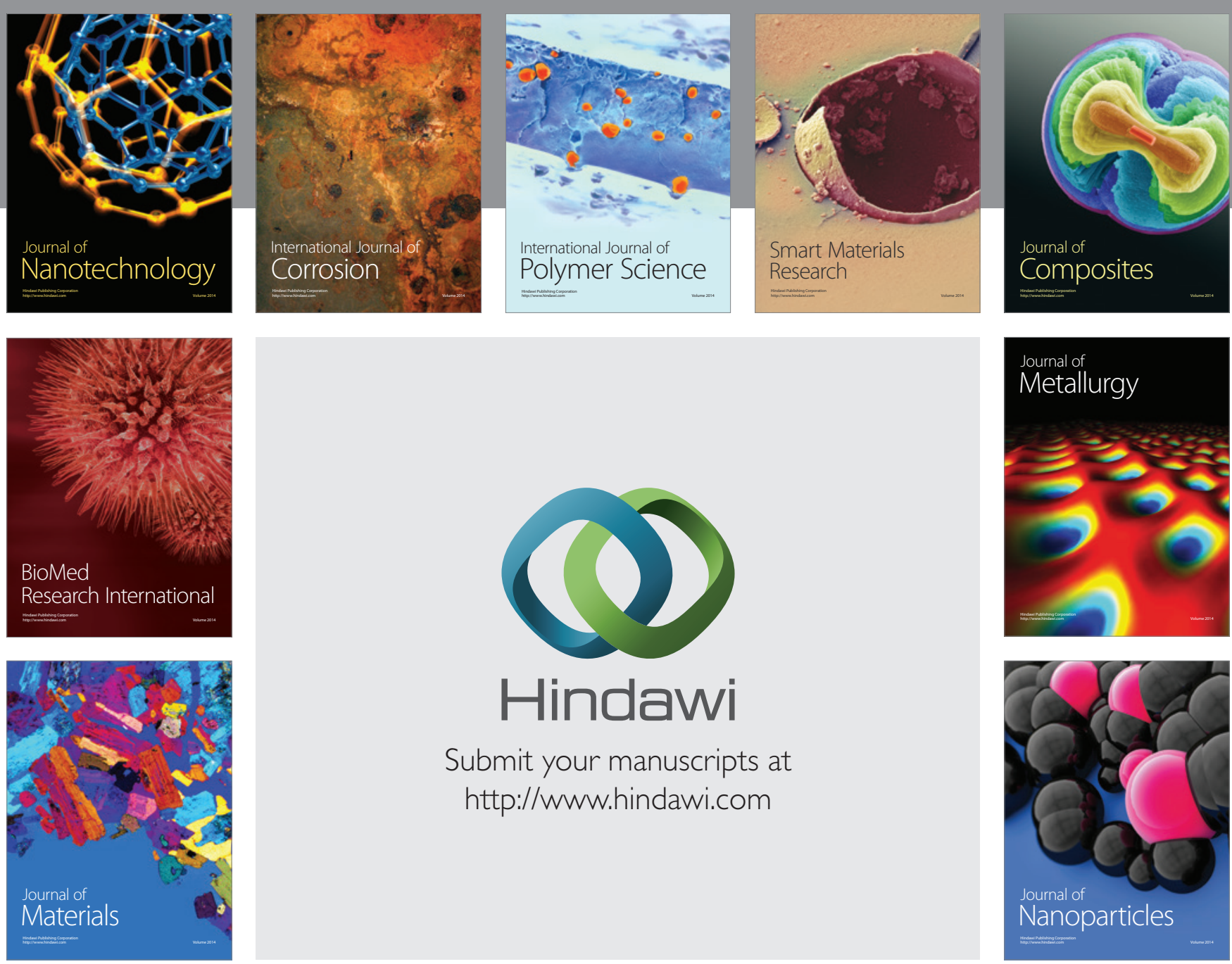

Submit your manuscripts at http://www.hindawi.com
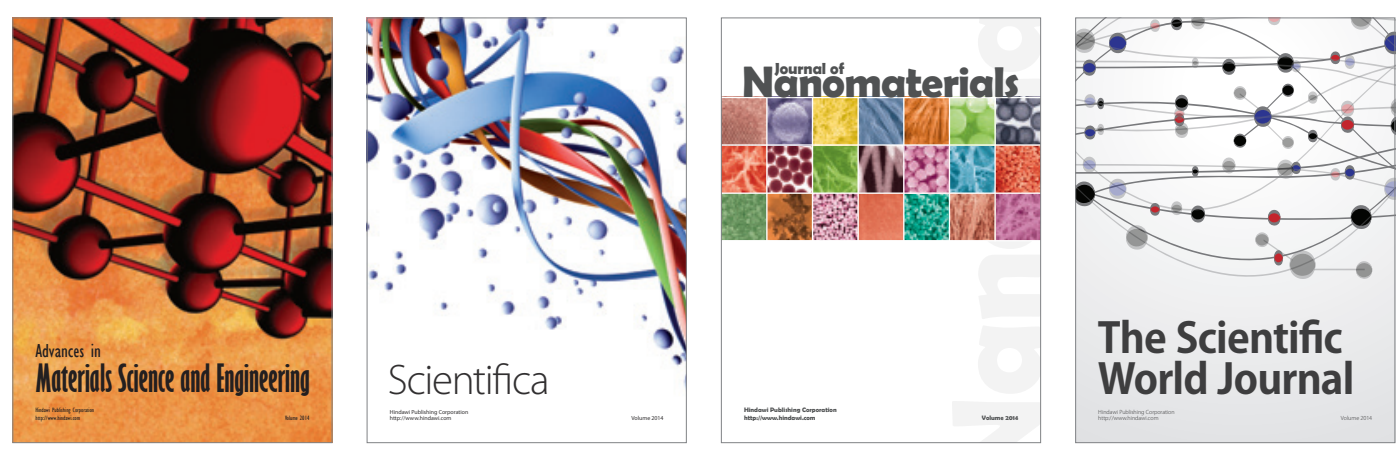

\section{The Scientific World Journal}
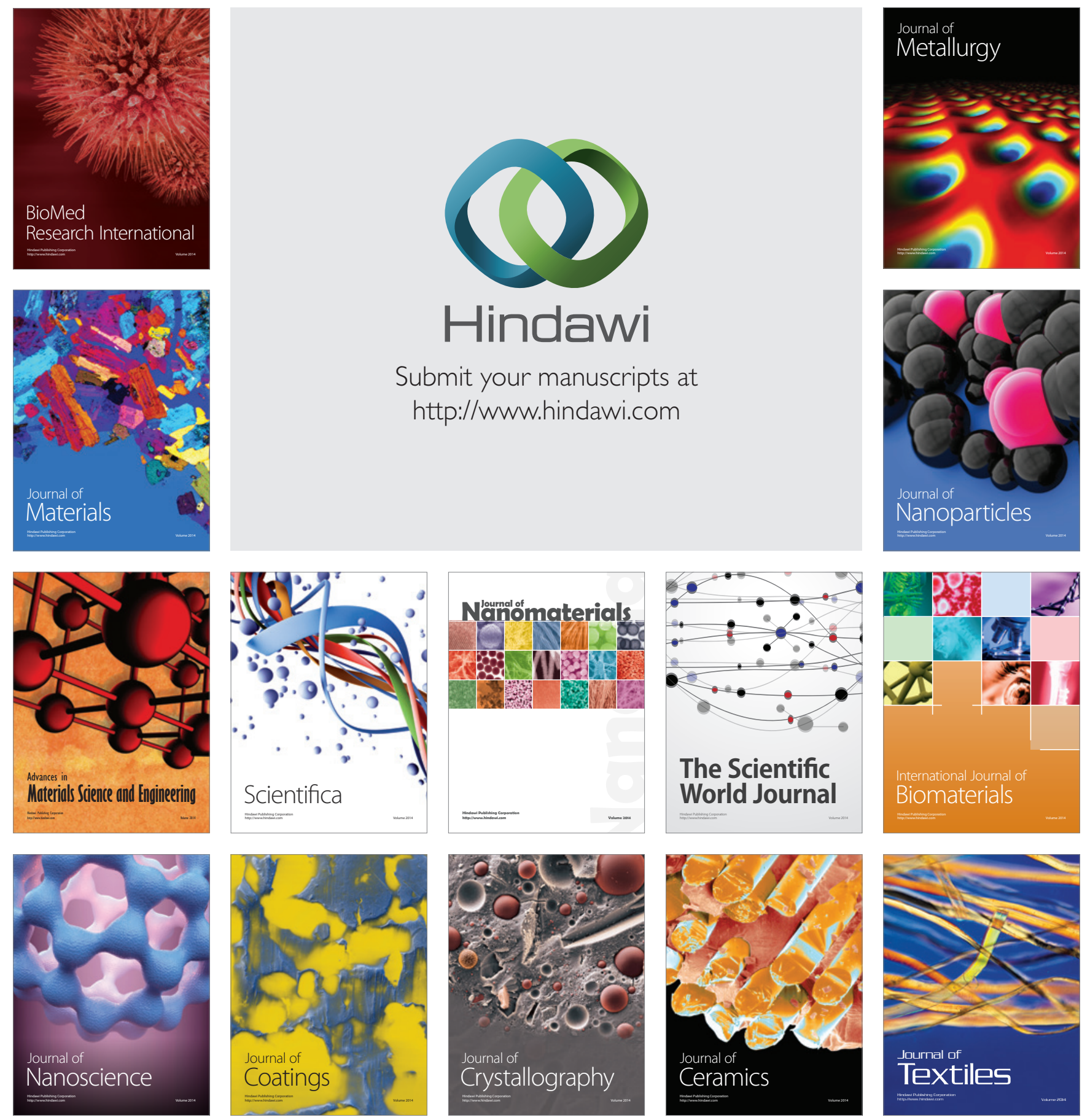